\title{
The importance of cholesterol medication adherence: the need for behavioral change intervention programs
}

This article was published in the following Dove Press journal:

Patient Preference and Adherence

\author{
Hayden B Bosworth ${ }^{1-5}$ \\ Barbara Ngouyombo ${ }^{6}$ \\ Jan Liska ${ }^{7}$ \\ Leah L Zullig', \\ Caroline Atlani ${ }^{8}$ \\ Anne $\mathrm{C} \mathrm{Beal}{ }^{7}$ \\ 'Center for Health Services Research \\ in Primary Care, Durham Veterans \\ Affairs Health Care System, Durham, \\ NC, USA; ${ }^{2}$ Department of Population \\ Health Sciences, Duke University, \\ Durham, NC, USA; ${ }^{3}$ School of \\ Nursing, Duke University, Durham, \\ NC, USA; ${ }^{4}$ Department of Psychiatry, \\ Duke University, Durham, NC, USA; \\ ${ }^{5}$ Department of Behavioral Sciences, \\ Duke University, Durham, NC, USA; \\ ${ }^{6}$ Value \& Access Team, Sanofi Pasteur, \\ Lyon, France; ${ }^{7}$ Center of Excellence \\ for Patient Centricity, Sanofi, Paris, \\ France; ${ }^{8}$ Patient Strategy, Diabetes \& \\ Cardiovascular Unit, Sanofi, Paris, \\ France
}

\begin{abstract}
Lipid-lowering medications have been shown to be efficacious, but adherence is suboptimal. This is a narrative, perspective review of recently published literature in the field of medication adherence research for lipid-lowering medications. We provide an overview of the impact of suboptimal adherence and use a World Health Organization framework (patient, condition, therapy, socioeconomic, and health system-related systems) to discuss factors that influence hyperlipidemia treatment adherence. Further, the review involves an evaluation of intervention strategies to increase hyperlipidemia treatment adherence with a special focus on mHealth interventions, patient reminders on packaging labels, nurse- and pharmacist-led interventions, and health teams. It also highlights opportunities for pharmaceutical companies to support and scale such behavioral interventions. Medication adherence remains a challenge for the long-term management of chronic conditions, especially those involving asymptomatic disease such as hyperlipidemia. To engage patients and enhance motivation over time, hyperlipidemia interventions must be targeted to individual patients' needs, with sequencing and frequency of contact tailored to the various stages of behavioral change.
\end{abstract}

Keywords: cardiovascular disease, compliance, health psychology, behavioral medicine, lifestyle

\section{Introduction}

Lipid-lowering medications, including statins, are among the most commonly prescribed medications. Adherence to these medications has been associated with a $25 \%$ decrease in the risk of cardiovascular disease (CVD). ${ }^{1}$ However, rates of lipid-lowering medication persistence are far from ideal. ${ }^{2}$ Improving adherence to lipid-lowering medication is critical to achieving optimal patient outcomes and achieving quality goals. ${ }^{3}$ This perspective will review the current field of adherence to lipid-lowering medications and focus on the role of behavioral interventions. Whenever possible we relied on meta-analyses, systematic reviews, and clinical trials and most of the work referenced is generalizable to the United States and other developed countries. We will also highlight the opportunities for pharmaceutical companies to serve as partners in efforts to promote medication adherence.

\section{Adherence to hyperlipidemia therapy}

Health Services Research and

Development (I52), Suite 600,

4II West Chapel Hill Street,

Durham, NC 2770I, USA

$\mathrm{Tel}+\mathrm{I} 9192866936$

Fax +I 9194165836

Email boswo00I@duke.edu
Medication adherence comprises three phases: 1) initiation of a new medication; 2) implementation (taking a medication according to dosing instructions); and 3) discontinuation (stopping a medication for any reason). ${ }^{4}$ Averaged across studies, only about half of patients achieve overall adherence (as defined by the achievement of a 
medication possession ratio [MPR] greater than $80 \%) .{ }^{5} \mathrm{MPR}$ is a common measure of medication adherence, particularly the implementation phase, and represents the number of dispensed medication doses divided by the number of days in a unit of time. Approximately 33\% to 50\% of patients discontinue statin medication within 1 year after treatment initiation and consistency of use decreases over time. ${ }^{6}$

\section{Impact of suboptimal adherence in hyperlipidemia}

Suboptimal adherence to lipid-lowering medications has been associated with increased medical costs. In fact, estimates of avoidable costs due to non-adherence to lipid-lowering medications exceed those for hypertension and diabetes combined. ${ }^{7}$ Adherence to statin therapy has been associated with lower all-cause health care costs. ${ }^{8}$

\section{Factors influencing hyperlipidemia treatment adherence}

Adherence is a multidimensional phenomenon determined by the interplay of patient factors, characteristics of medication regimens, and health care system factors. The World Health Organization categorized potential reasons for medication non-adherence into five broad groups that reflect patient, condition, therapy, socioeconomic, and health system-related factors. ${ }^{9}$

At a patient level, several factors may influence adherence, including patients' knowledge and beliefs about their illness, their readiness and long-term motivation to manage the issue, confidence in their ability to engage and keep up with illness-management behaviors, and their expectations regarding the outcome of treatment. ${ }^{10}$ Forgetfulness, competing priorities, decisions to omit doses, lack of information, emotional factors, perceived side effects, and recent initiation of treatment, as well as inadequate literacy, may also affect adherence. ${ }^{7}$ These factors are not typically noted in electronic medical records, yet may be critical to predicting adherence to treatment.

Because of the asymptomatic and chronic nature of hyperlipidemia, patients may also perceive no immediate benefit to treatment yet experience adverse side effects from it. Without appreciating the potential serious and long-term consequences of their condition, patients often adhere poorly to, or completely disengage in, cholesterol management therapy. ${ }^{11}$ Therefore, educating patients about the potential health effects of hyperlipidemia is key to promoting adherence.

A specific challenge to adherence to cholesterol treatment is the perceived and actual cholesterol intolerance. A major cause of statin non-adherence is statin-attributed muscular symptoms (SAMS), which ranges from rhabdomyolysis to the more common conditions of myalgia, weakness, and fatigue that may or may not be associated with laboratory abnormalities. Recent guidelines recommended a unifying definition of statin SAMS, where the pathophysiology, diagnosis, and the management were comprehensively present. Meta-analyses of blinded, placebo-controlled statin trials find that the incidence of SAMS is $2 \%-3 \%$; however, prevalence is $10 \%-25 \%$ in observational studies.

Certain characteristics of the medication regimen, such as taking fewer medications, initiating therapy with other cardiovascular medications, and lower patient cost sharing, are consistently associated with better adherence or persistence to treatment. ${ }^{6}$ Better adherence is also associated with the length of time spent and frequency of provider office visits and patients' perceived efficacy of therapy. ${ }^{12}$ While numerous factors influence adherence behaviors, much remains to be understood about recognizing, prioritizing, and responding to them to design more effective approaches to improving medication adherence.

There are also barriers to optimal treatment from the providers' perspective, including providers' failure to titrate statin dose appropriately, which might cause a false impression that the lipid-lowering effect of a statin is inadequate, and physicians prescribing less potent statins instead of more potent ones when needed. Two factors influence this: 1) lack of acceptable knowledge and education, mainly in general practitioners; and 2) fear of statin-related adverse effects.

\section{Increasing hyperlipidemia treatment adherence: effective strategies}

Because medication non-adherence is often multifactorial, interventions must adopt comprehensive approaches to achieve effectiveness. In general, multifactorial, tailored approaches are more effective than one-size-fits-all approaches. In a recent meta-analysis, nearly all of the interventions effective at promoting long-term adherence were complex, including combinations of more convenient care, information, reminders, self-monitoring, reinforcement, counseling, telephone follow-up, and supportive care. ${ }^{13}$ In the context of lipidlowering medications, interventions that include treatment intensification may be particularly helpful to improve both short- and long-term adherence. ${ }^{14}$ Patient-related factors account for the largest incremental gains in predicting adherence. In the following sections, we describe selected evidence-based strategies to promote medication adherence (summary of studies shown in Table 1). 
Table I Summary of studies

\begin{tabular}{|c|c|c|c|c|c|}
\hline Author, year & Country & Patient population & $\begin{array}{l}\text { Clinical } \\
\text { condition(s) }\end{array}$ & $\begin{array}{l}\text { Primary/secondary } \\
\text { prevention }\end{array}$ & $\begin{array}{l}\text { Adherence measurement } \\
\text { approach }\end{array}$ \\
\hline Bansilal et al, $2016^{36}$ & USA & $\begin{array}{l}\text { Adults post-myocardial } \\
\text { infarction and adults with } \\
\text { atherosclerotic disease }\end{array}$ & $\begin{array}{l}\text { Myocardial } \\
\text { infarction, } \\
\text { atherosclerotic } \\
\text { disease }\end{array}$ & Secondary prevention & Insurance claims data \\
\hline Bosworth et al, 201721 & USA & $\begin{array}{l}\text { US military veteran patients } \\
\text { in Durham Veterans Affairs } \\
\text { Medical Center ambulatory } \\
\text { care clinics }\end{array}$ & $\begin{array}{l}\text { Elevated } \\
\text { low-density } \\
\text { lipoprotein } \\
\text { cholesterol }\end{array}$ & Secondary prevention & $\begin{array}{l}\text { Pharmacy refill data, } \\
\text { medication possession ratio }\end{array}$ \\
\hline Brookhart et al, $2007^{12}$ & USA & $\begin{array}{l}\text { Adults who began statin } \\
\text { treatment within } 12 \text { months }\end{array}$ & $\begin{array}{l}\text { Myocardial } \\
\text { infarction and } \\
\text { cardiovascular } \\
\text { disease }\end{array}$ & Secondary prevention & $\begin{array}{l}\text { Electronic monitor, } \\
\text { prescription refill data }\end{array}$ \\
\hline Chow et al, 201520 & Australia & $\begin{array}{l}\text { Ethnically diverse group } \\
\text { of adults with varied } \\
\text { socioeconomic status }\end{array}$ & $\begin{array}{l}\text { Coronary heart } \\
\text { disease }\end{array}$ & Secondary prevention & $\begin{array}{l}\text { 6-month follow-up } \\
\text { appointments measuring } \\
\text { low-density lipoprotein } \\
\text { cholesterol, blood } \\
\text { pressure, cholesterol, waist } \\
\text { circumference, heart rate, } \\
\text { total physical activity, and } \\
\text { smoking status }\end{array}$ \\
\hline Franklin et al, $2006^{33}$ & USA & Patients age $8-18$ years & Type I diabetes & Secondary prevention & Self-reported data \\
\hline Gibson et al, $2012^{6}$ & USA & $\begin{array}{l}\text { Adults age I8-64 identified } \\
\text { with gaps in adherence to } \\
\text { statin therapy }\end{array}$ & $\begin{array}{l}\text { Cardiovascular } \\
\text { disease }\end{array}$ & Secondary prevention & $\begin{array}{l}\text { Claims data, pharmacy refill } \\
\text { data }\end{array}$ \\
\hline Huser et al, $2005^{5}$ & USA & $\begin{array}{l}\text { Adults prescribed statin } \\
\text { therapy }\end{array}$ & $\begin{array}{l}\text { Cardiovascular } \\
\text { disease }\end{array}$ & Secondary prevention & $\begin{array}{l}\text { Pharmacy refill data, } \\
\text { medication possession ratio }\end{array}$ \\
\hline Jackevicius et al, 2002"I & Canada & $\begin{array}{l}\text { Adults } 66 \text { and over currently } \\
\text { prescribed statins or not } \\
\text { prescribed statins }\end{array}$ & $\begin{array}{l}\text { Acute coronary } \\
\text { syndrome, } \\
\text { coronary artery } \\
\text { disease }\end{array}$ & $\begin{array}{l}\text { Separate primary and } \\
\text { secondary prevention } \\
\text { groups }\end{array}$ & $\begin{array}{l}\text { Claims data, prescription } \\
\text { refill data, insurance plan } \\
\text { database, hospital discharge } \\
\text { database }\end{array}$ \\
\hline Johnson et al, $2006^{31}$ & USA & $\begin{array}{l}\text { Adults age } 2 \mathrm{I}-85 \text { with high } \\
\text { cholesterol }\end{array}$ & High cholesterol & Secondary prevention & Self-reported data \\
\hline $\begin{array}{l}\text { Lauffenburger et al, } \\
2017^{27}\end{array}$ & USA & $\begin{array}{l}\text { Adults } 18 \text { or over who } \\
\text { began oral hypoglycemic, } \\
\text { antihypertensive, or } \\
\text { cholesterol medication } \\
\text { therapy between } 2011 \text { and } \\
2013\end{array}$ & $\begin{array}{l}\text { Hypoglycemia, } \\
\text { hypertension, } \\
\text { high cholesterol }\end{array}$ & Secondary prevention & Insurance claims data \\
\hline $\begin{array}{l}\text { Maciejewski et al, } \\
2014^{37}\end{array}$ & USA & $\begin{array}{l}\text { US military veteran patients } \\
\text { from Durham Veterans } \\
\text { Affairs Medical Center } \\
\text { ambulatory care clinics }\end{array}$ & Hypertension & Secondary prevention & Self-reported data \\
\hline Pittman et al, $201 \mathrm{I}^{8}$ & USA & $\begin{array}{l}\text { Adults age }|8-6| \text { prescribed } \\
\text { statins }\end{array}$ & $\begin{array}{l}\text { Cardiovascular } \\
\text { disease }\end{array}$ & Secondary prevention & $\begin{array}{l}\text { Claims data, pharmacy refill } \\
\text { data, medication possession } \\
\text { ratio }\end{array}$ \\
\hline Shaw et al, $2013^{34}$ & USA & $\begin{array}{l}\text { Adults age } 18 \text { or over } \\
\text { recruited from Duke Diet } \\
\text { and Fitness Center }\end{array}$ & Obesity & Secondary prevention & Self-reported data \\
\hline Vinogradova et al, $2016^{2}$ & UK & $\begin{array}{l}\text { Adults age } 25-84 \text { without } \\
\text { cardiovascular disease and } \\
\text { those taking statins }\end{array}$ & $\begin{array}{l}\text { Cardiovascular } \\
\text { disease }\end{array}$ & $\begin{array}{l}\text { Separate primary and } \\
\text { secondary prevention } \\
\text { groups }\end{array}$ & Pharmacy refill data \\
\hline
\end{tabular}

\section{mHealth interventions}

Approaches that seek to promote adherence by communicating with patients via their mobile phones or other wireless communication devices are often described as
"mHealth" interventions. Given the high penetration of mobile phones (90\% in developing countries and $96 \%$ globally), such approaches can be broadly scaled. ${ }^{15}$ Among the most frequently utilized mobile communication channels is 
short message service (SMS), or text messaging, used by an estimated three quarters of those with mobile phones. Text messages can be sent quickly at low cost and can be easily automated. Text-messaging interventions can also incorporate qualities often associated with effective health communication, such as tailoring, interactivity, personalization, and/or frequent repetition. ${ }^{16}$ Furthermore, text messages appeal to users' desire to receive messages and the pleasure associated with this reward. ${ }^{17}$ Ninety-nine percent of mobile text messages are opened, and $90 \%$ are read within 3 minutes of being received. ${ }^{18}$

One review suggests that medication adherence increased in all studies that applied tailored or personalized text messages and that most patients reported high satisfaction (>80\%) in receiving SMS messages for health management. ${ }^{19}$ A recent study of a support program that delivered four text messages per week for 6 months resulted in significant decreases in levels of low-density lipoprotein cholesterol (LDL-C), systolic blood pressure, smoking, and body mass index as well as significant increases in physical activity. ${ }^{20}$ The text messages provided advice, motivational reminders, and support to change lifestyle behaviors.

\section{Packaging interventions}

Medication packaging designed with messages and reminders for patients may positively impact adherence. A recent randomized controlled trial focused on the effects of blister packaging on behavior among patients at risk for CVD. ${ }^{21}$ Patients in the intervention group received their medication in special blister packaging labeled for daily use with reminders to take their medication. Overall, while not statistically different, $54 \%$ of the intervention group adhered per MPR over 12 months compared to $47 \%$ of the control group, which received only general education (difference $=7.6 \%$; 95\% CI: $-5 \%, 20 \%$ ).

\section{Nurse-delivered interventions}

Nurse-delivered interventions may be another effective mechanism to promote optimal adherence. A recent review examined 18 randomized controlled trials involving nursecoordinated care (including 11,195 patients in total) in the context of secondary prevention of CVD. Compared with usual care, nurse-delivered interventions resulted in patients having lower systolic blood pressure (weighted mean difference $2.96 \mathrm{mmHg}$; $95 \% \mathrm{CI}, 1.53$ to $4.40 \mathrm{mmHg}$ ) and reduced LDL-C (weighted mean difference $0.23 \mathrm{mmol} / \mathrm{L} ; 95 \% \mathrm{CI}$, 0.10 to $0.36 \mathrm{mmol} / \mathrm{L}){ }^{22}$

\section{Pharmacist-delivered interventions}

Pharmacist-delivered interventions may also improve adherence to lipid-lowering medications. In one review, 30 randomized controlled trials (involving a total of 11,765 patients) were identified. Interventions conducted exclusively by pharmacists or implemented by pharmacists collaborating with physicians or nurses involved patient education and counseling about medications, lifestyle, or compliance; patient reminder systems; measurement of CVD risk factors; medication management (eg, medical record review or adjustment or change of medications); feedback to physicians; and education of health care professionals. Such interventions were associated with significant reductions in total cholesterol (nine studies involving 1,121 patients; $-17.4 \mathrm{mg} / \mathrm{L}$ [95\% CI, -25.5 to -9.2$]$ ) and LDL-C (seven studies involving 924 patients; $-13.4 \mathrm{mg} / \mathrm{L}[95 \%$ CI, -23.0 to -3.8$]) .^{23}$

\section{Physician-led interventions}

Primary care physicians and specialists have an important, yet largely unrealized, opportunity to promote medication adherence. Providers should assess their patients' likely adherence, taking into account risk factors for non-adherence as well as proven strategies to increase adherence and tailor interventions to patients' needs. Some practical approaches include anticipating common misperceptions (eg, that lipidlowering medication can be stopped when the prescription runs out); minimizing the complexity of treatment regimens (eg, once-daily dosing and appropriate combination drugs); reducing polypharmacy; and using positive reinforcement (eg, offering congratulations if patients are following treatment plans). Providers can play a central role in achieving patients' buy-in, keeping treatment regimens simple and focused, and evaluating improvement. Providers will need support from other parts of the health care system to achieve these aims. For example, patients with low health literacy may benefit from easy-to-understand educational materials, chronic disease management programs, better medication drug labeling, and communication training for clinicians. ${ }^{6}$

\section{Patient-centered interventions}

Evidence increasingly demonstrates that accounting for patients' beliefs, preferences, goals, and barriers to medication use (eg, cost, technological ability, or concerns about medication prescribing and use) can lead to better clinical outcomes. ${ }^{24}$ Offering patients choices can help to ensure the selected treatment is most desirable in terms of timing, duration, and its potential physical, emotional, and social 
effects. $^{25}$ The spread of payment models that hold health care organizations and clinicians accountable for poor patient outcomes and downstream costs may produce greater interest in improving medication adherence by promoting patientcentered care.

\section{The role of health teams in optimal medication use}

Findings from a recent review suggest that interventions using a team approach are effective in improving cardiovascular medication adherence, with a growing body of literature supporting nurse/physician or pharmacist/physician team approaches. ${ }^{26}$ For this reason, interventions may be especially effective when provided by care teams working in patient-centered medical home, where patients have ongoing relationships with their primary care providers that enable proactive care, both in terms of rigorously assessing risk factors and health issues and addressing them. ${ }^{27}$

\section{The role of pharmaceutical companies in promoting effective intervention strategies}

In addition to their investments in research, development, and commercialization of medications, pharmaceutical companies are increasingly offering disease management and/or medication support programs to help patients follow their providers' treatment recommendations. These initiatives are part of a broader shift to engage patients in treatment and health care decision making (eg, through cost-sharing models designed to make patients more sensitive to the costs of treatment). Enabled by technology that allows patients to collect and exchange health data, these programs enable the pharmaceutical industry to measure the outcomes that matter most to patients.

As partners with health care providers and payers, pharmaceutical companies today are committed to ensuring patient access to innovative and lifesaving drugs through contracts that offer performance guarantees linked on outcomes - ie, actual LDL lowering effects of new treatments for dyslipidemia or real-life drug utilization. This sharing of risk and responsibility enables patients who can most benefit from the drug to receive it while continuing to encourage utilization of lower-cost statins for the majority of patients.

Pharmaceutical companies can also leverage their extensive patient outreach activities to promote and facilitate appropriate use of their products to improve adherence - and ultimately outcomes. For example, patient support programs (PSPs), including medication management and counseling, can promote medication adherence, particularly among patients with chronic conditions who may have complex treatment regimens as well as for those on medications prescribed from specialty pharmacies. PSPs can also serve as sources of data to study and better understand how to address patient needs to improve adherence. Depending on the regulatory environment, such programs might help patients in a variety of ways - from figuring out their next steps after receiving a diagnosis to securing financial assistance, connecting with other patients and community experts, or providing clinical education and better understanding of their treatment.

In a recent review of 64 varied PSPs led by pharmaceutical companies, ${ }^{28}$ all of the programs targeted patients with chronic diseases and the majority $(48$, or $75 \%)$ offered in-clinic, face-to-face support. All but nine (14.1\%) were overseen by allied health care professionals (eg, nurses, pharmacists, or paraprofessionals). The most frequent clinical outcome impacted by the programs was treatment adherence - with 27 of 41 programs (66\%) reporting increased adherence. Only 15 (23.4\%) programs reported cost or utilization-related outcomes and, of these, 12 reported positive outcomes. Further research is needed to clarify which support programs, delivery methods, and components offer the greatest value for particular medical conditions.

\section{Design and personalization of novel hyperlipidemia intervention}

This final section describes principles and methods for implementing effective treatment adherence programs for hyperlipidemia, many of which could be used to encourage adherence to treatment for other chronic diseases. We discuss specific issues related to developing interventions, cost optimization, and sustaining intervention effects.

\section{Intervention design}

\section{Tailoring and targeting}

Interventions to promote treatment adherence are most effective when they are personalized and tailored to patients' needs. Many interventions tailor messages to particular patient populations (eg, defined by their age, disease, or other characteristics). ${ }^{29}$ Over time, as access to data on prescribing patterns and medication use increases, and as predictive analytics improve, such methods have become more focused - so that messages can be customized based not on population factors but on more proximate and individualized determinants of health behaviors, such as beliefs about the risks and benefits of treatment. Behavioral interventions 
could, eg, leverage the particular influences most relevant and most likely to engage particular individuals. In the case of hyperlipidemia (an asymptomatic disease), tailoring educational material to address a patient's perception of the risk of the condition and benefit of medication could promote adherence. It is also important to target interventions based on primary adherence or secondary prevention; this has been a problem that has limited interpretation of findings.

The general approach to tailoring health communication is to create messages that are individualized for each recipient based on patient-reported measures. The aim is to influence behavior by communicating in a way that appears to be relevant only to the recipient. Information processing theory suggests that people are more likely to process information thoughtfully when they perceive it to be personally relevant. The benefits of tailoring messages include longer retention and increased likelihood of permanent attitude change. ${ }^{30}$

Message tailoring also promotes appropriate medication use among patients with hypertension, schizophrenia, hyperlipidemia, and asthma. ${ }^{31}$ Most studies focused on improving medication adherence using text messages focus on unintentional non-adherence (ie, forgetting to take medication) by sending reminder messages, and results are mixed in terms of their effect on medication use. ${ }^{32}$ Several studies combined mobile phone adherence reminders and tailored messages addressing patients' beliefs associated with intentional nonadherence. ${ }^{33}$

\section{Sequencing and frequency of contact}

There may be differences in the optimal timing and frequency of contacts, depending on the mode of communication (eg, telephone calls vs text messaging). For text messaging, $90 \%$ of people respond within 10 minutes of receiving a text message. When individuals were asked when they would prefer to receive text messages, most said they preferred to be contacted early in the morning. Research indicates that sending SMS messages at approximately 8 am drove the highest open rate. ${ }^{34}$

For case management calls that are linked to clinical visits or other encounters, it is important to develop a tracking database that enables the scheduling of follow-up calls. It is also important to be able to reach people when they are more likely to be home; call centers that only operate during typical work hours (eg, 9 am to 5 pm) are less likely to reach people.

\section{Cost optimization}

Understanding the relative cost-effectiveness of different approaches may guide the design and implementation of efforts to increase adherence. From a payer perspective, an effective intervention strategy must not only improve adherence to lipid-lowering medication and thereby help to reduce cholesterol levels, but also reduce the cost of care. One study sought to compare the cost-effectiveness of different interventions that improve adherence to antihypertensive and lipid-lowering therapy. Reminders and educational materials, and care management programs led by pharmacists and nurses appear cost-effective. ${ }^{35}$

Full adherence to guideline-recommended therapies for hyperlipidemia is associated with a lower rate of major adverse cardiovascular events and cost savings, with a threshold effect at $>80 \%$ adherence among those with a history of myocardial infarctions. ${ }^{36}$ At least a $40 \%$ level of long-term adherence must be maintained to continue to accrue these benefits.

Novel behavioral approaches to improving medication adherence may significantly reduce cardiovascular events. Pharmaceutical companies can help bring these interventions to scale worldwide, making them the standard of care especially for chronic condition management, including hyperlipidemia. Tailoring interventions to meet the needs of particular patient groups may hold several advantages. First, such an approach could potentially capture the attention of a broader cross-section of patients than would a "one-size-fits-all" approach. Tailored interventions also may be more cost effective as the resources expended may yield the greatest impacts. Finally, tailored interventions focus on individuals' response to treatment, thereby placing patients' experiences at their center.

\section{Sustainability of improved medication adherence outcomes}

In general, few studies have examined maintenance of effects after conclusion of an intervention. ${ }^{37}$ Moreover, previous trials relied on initial intensive intervention for all with a decrease in intensity over time irrespective of improvements, raising concerns about the potential for sustainability of intensive intervention effects. The stepped-care approach to hypertension pharmacologic therapy, ${ }^{38}$ which matches the level of treatment intensity to complexity of the condition, offers a model for hyperlipidemia intervention design. Here again, pharmaceutical companies can play a supportive role by elucidating the factors that drive patient empowerment and lasting behavioral change and by disseminating evidencebased research findings on benefits of patient adherence interventions. In addition, pharmaceutical companies can help ensure the sustainability and evaluation of PSPs by demonstrating their impact on improving outcomes, including 
patient empowerment, behavioral change, and ability to selfmanage and interact with health care professionals.

In general, more effective communication between providers and their patients to discuss potential adverse effects, to establish pharmacological and non-pharmacological goals of the therapy, and to stress the importance of continuing treatment with high-dose statins in order to prevent acute CV events, should help improve long-term adherence. Recent studies have also demonstrated the efficacy of PCSK9 inhibitors in reducing LDL-C and non-high-density lipoprotein cholesterol and have confirmed their safety profile for the highest risk patients. These new classes of medicines will provide additional options and clinical benefits to these high risk individuals.

\section{Conclusion}

Medication adherence remains a challenge for the longterm management of chronic conditions, especially those involving asymptomatic disease such as hyperlipidemia. Multifaceted patient interventions involving behavioral change that combine mHealth solutions with face-to-face interventions by physicians, nurses, pharmacists, and other caregivers appear to be the most effective drivers of medication adherence for hyperlipidemia. To engage patients and enhance motivation over time, hyperlipidemia interventions must be targeted to individual patients' needs, with sequencing and frequency of contact tailored to the various stages of behavioral change.

The patient's role in decision making and their expectations of health care companies are changing as patients become more aware of the impact of behavior on health outcomes and gain access to technologies that empower them with information and the ability to play a more active role in managing their health. This may be increasingly important as patients bear a greater share of costs. Providers and pharmaceutical companies can support them with interventions that emphasize patient empowerment, behavior change, and informed decision making. By helping bringing such interventions to scale, pharmaceutical companies can help make them cost effective and sustainable.

\section{Acknowledgment}

We would like to acknowledge the assistance of Ms Christiana Oshotse and Sarah Gonzalez in updating the table, references, and submitting.

\section{Disclosure}

Ms Ngouyombo, Mr Liska, Drs Atlani and Beal are employees of Sanofi. Dr Bosworth's research is funded by NIH, VA,
Johnson \& Johnson, and Pharma foundation. He reports receiving consulting fees from Sanofi, Otsuku, Genentech, and Boehringer Ingelheim. Dr Bosworth was supported by research career scientist award from the VA Health Service Research and Development (VA HSR\&D 08-027). Dr Zullig was supported by HSRD CDA award (CDA 13-025). The other authors report no conflicts of interest.

\section{References}

1. DiMatteo MR, Giordani PJ, Lepper HS, Croghan TW. Patient adherence and medical treatment outcomes: a meta-analysis. Med Care. 2002;40(9):794-811.

2. Vinogradova Y, Coupland C, Brindle P, Hippisley-Cox J. Discontinuation and restarting in patients on statin treatment: prospective open cohort study using a primary care database. BMJ. 2016;353:i3305.

3. ncqa.org [homepage on the Internet]. HEDIS 2016 Final NDC Lists. National Committee for Quality Assurance. Available from: https:// www.ncqa.org/hedis-quality-measurement/hedis-measures/hedis2016/hedis-2016-ndc-license/hedis-2016-final-ndc-lists. Accessed January 26, 2018.

4. Vrijens B, De Geest S, Hughes DA, et al. A new taxonomy for describing and defining adherence to medications. Br J Clin Pharmacol. 2012; 73(5):691-705.

5. Huser MA, Evans TS, Berger V. Medication adherence trends with statins. Adv Ther. 2005;22(2):163-171.

6. Gibson TB, Fendrick AM, Gatwood J, Chernew ME. Gaps in treatment, treatment resumption, and cost sharing. Am J Pharm Benefits. 2012;4:e159-e165.

7. Bosworth HB, Granger BB, Mendys $\mathrm{P}$, et al. Medication adherence: a call for action. Am Heart J. 2011;162(3):412-424.

8. Pittman DG, Chen W, Bowlin SJ, Foody JM. Adherence to statins, subsequent healthcare costs, and cardiovascular hospitalizations. Am J Cardiol. 2011;107(11):1662-1666.

9. World Health Organization. Adherence to long-term therapies: Evidence for action. Geneva: World Health Organization, 2003. Available from: http://www.who.int/chp/knowledge/publications/adherence_report/en/. Access date February 07, 2018.

10. Casula M, Tragni E, Catapano AL. Adherence to lipid-lowering treatment: the patient perspective. Patient Prefer Adherence. 2012;6:805-814.

11. Jackevicius CA, Mamdani M, Tu JV. Adherence with statin therapy in elderly patients with and without acute coronary syndromes. JAMA. 2002;288(4):462-467.

12. Brookhart MA, Patrick AR, Schneeweiss S, et al. Physician follow-up and provider continuity are associated with long-term medication adherence: a study of the dynamics of statin use. Arch Intern Med. 2007;167(8):847-852.

13. Nieuwlaat R, Wilczynski N, Navarro T, et al. Interventions for enhancing medication adherence. Cochrane Database Syst Rev. 2014;(11): CD000011.

14. van Driel ML, Morledge MD, Ulep R, Shaffer JP, Davies P, Deichmann R. Interventions to improve adherence to lipid-lowering medication. Cochrane Database Syst Rev. 2016;12:CD004371.

15. International Telecommunication Union. ICT Facts and Figures. Geneva: International Telecommunication Union; 2014. Available from: http://www.itu.int/en/ITU-D/Statistics/Documents/facts/ ICTFactsFigures2014-e.pdf. Accessed January 29, 2018.

16. Pew Research Center. Global Digital Communication: Texting, Social Networking Popular Worldwide. Washington, DC: Pew Research Center; 2011. Available from: http://www.pewglobal.org/files/2011/12/ Pew-Global-Attitudes-Technology-Report-FINAL-December-20-2011. pdf. Accessed January 29, 2018.

17. psychologytoday.com [homepage on the Internet]. Are you addicted to texting? Psychology today; 2014. Available from: http://www.psychologytoday.com/blog/brain-wise/201408/are-you-addicted-texting. Accessed January 29, 2018. 
18. tatango.com [homepage on the Internet]. SMS open rates exceed $99 \%$. Tatango; 2013. Available from: https://www.tatango.com/blog/smsopen-rates-exceed-99/. Accessed January 29, 2018.

19. Park LG, Howie-Esquivel J, Dracup K. A quantitative systematic review of the efficacy of mobile phone interventions to improve medication adherence. J Adv Nurs. 2014;70(9):1932-1953.

20. Chow CK, Redfern J, Hillis GS, et al. Effect of lifestyle-focused text messaging on risk factor modification in patients with coronary heart disease: a randomized clinical trial. JAMA. 2015;314(12): 1255-1263.

21. Bosworth H, Brown JN, Danus S, et al. Evaluation of a packaging approach to improve cholesterol medication adherence. Am J Manag Care. 2017;23(9):e280-e286.

22. Snaterse M, Dobber J, Jepma P, et al. Effective components of nursecoordinated care to prevent recurrent coronary events: a systematic review and meta-analysis. Heart. 2016;102(1):50-56.

23. Santschi V, Chiolero A, Burnand B, Colosimo AL, Paradis G. Impact of pharmacist care in the management of cardiovascular disease risk factors: a systematic review and meta-analysis of randomized trials. Arch Intern Med. 2011;171(16):1441-1453.

24. van Boven JF, Stuurman-Bieze AG, Hiddink EG, Postma MJ, Vegter S. Medication monitoring and optimization: a targeted pharmacist program for effective and cost-effective improvement of chronic therapy adherence. J Manag Care Pharm. 2014;20(8):786-792.

25. Fagerlin A, Pignone M, Abhyankar P, et al. Clarifying values: an updated review. BMC Med Inform Decis Mak. 2013;13 Suppl 2:S8.

26. Carter BL, Rogers M, Daly J, Zheng S, James P. The potency of teambased care interventions for hypertension: a meta-analysis. Arch Intern Med. 2009;169(19):1748-1755.

27. Lauffenburger JC, Shrank WH, Bitton A, et al. Association between patient-centered medical homes and adherence to chronic disease medications: a cohort study. Ann Intern Med. 2017;166(2):81-88.

28. Ganguli A, Clewell J, Shillington AC. The impact of patient support programs on adherence, clinical, humanistic, and economic patient outcomes: a targeted systematic review. Patient Prefer Adherence. 2016;10:711-725.
29. Kreuter MW, Wray RJ. Tailored and targeted health communication: strategies for enhancing information relevance. Am J Health Behav. 2003;27 Suppl 3:S227-S232.

30. Petty R, Cacioppo J. Communication and Persuasion: Central and Peripheral Routes to Attitude Change. New York: Springer-Verlag; 1986.

31. Johnson SS, Driskell MM, Johnson JL, et al. Transtheoretical model intervention for adherence to lipid-lowering drugs. Dis Manag. 2006;9(2):102-114.

32. Vervloet M, Linn AJ, van Weert JC, de Bakker DH, Bouvy ML, van Dijk L. The effectiveness of interventions using electronic reminders to improve adherence to chronic medication: a systematic review of the literature. J Am Med Inform Assoc. 2012;19(5):696-704.

33. Franklin VL, Waller A, Pagliari C, Green SA. A randomized controlled trial of Sweet Talk, a text-messaging system to support young people with diabetes. Diabet Med. 2006;23(12):1332-1338.

34. Shaw RJ, Bosworth HB, Hess JC, et al. Development of a theoretically driven mHealth text messaging application for sustaining recent weight loss. JMIR Mhealth and Uhealth. 2013;1(1):e5.

35. Chapman RH, Kowal SL, Cherry SB, Ferrufino CP, Roberts CS, Chen L. The modeled lifetime cost-effectiveness of published adherenceimproving interventions for antihypertensive and lipid-lowering medications. Value Health. 2010;13(6):685-694.

36. Bansilal S, Castellano JM, Garrido E, et al. Assessing the impact of medication adherence on long-term cardiovascular outcomes. $\mathrm{J} \mathrm{Am}$ Coll Cardiol. 2016;68(8):789-801.

37. Maciejewski ML, Bosworth HB, Olsen MK, et al. Do the benefits of participation in a hypertension self-management trial persist after patients resume usual care? Circ Cardiovasc Qual Outcomes. 2014;7(2):269-275.

38. Cohen JD, Grimm RH Jr, Smith WM. Multiple risk factor intervention trial (MRFIT). Prev Med. 1981;10(4):501-518.
Patient Preference and Adherence

\section{Publish your work in this journal}

Patient Preference and Adherence is an international, peer-reviewed, open access journal that focuses on the growing importance of patient preference and adherence throughout the therapeutic continuum. Patient satisfaction, acceptability, quality of life, compliance, persistence and their role in developing new therapeutic modalities and compounds to optimize

\section{Dovepress}

clinical outcomes for existing disease states are major areas of interest for the journal. This journal has been accepted for indexing on PubMed Central. The manuscript management system is completely online and includes a very quick and fair peer-review system, which is all easy to use. Visit http://www. dovepress.com/testimonials.php to read real quotes from published authors. 